\title{
Impact on Socio-Economic Transformation of Agriculture Development In Saharanpur District- A Geographical Study
}

\author{
Dr. Vijay kumar
}

Abstract

\author{
Reference to this paper \\ should be made as \\ follows: \\ Dr. Vijay kumar \\ Impact on Socio- \\ Economic \\ Transformation of \\ Agriculture \\ Development In \\ Saharanpur District- \\ A Geographical \\ Study \\ Journal Global Values \\ Vol. XI, No.I \\ Article No.7 \\ pp. 51-56 \\ http://anubooks.com/ \\ ?page_id $=6195$ \\ https://doi.org/ \\ 10.31995/ \\ jgv.2020.v11i01.007
}


Impact on Socio-Economic Transformation of Agriculture Development In Saharanpur District-

A Geographical Study

Dr. Vijay kumar

\section{Introduction}

In India, after independence, there has been an all-round development whether it is in agriculture, industry, population or livestock. Yes, one thing is certain that the development has not been at the same pace as in other countries. There have been numerous physical, social and political factors responsible for it. Agriculture has been the backbone of Indian economy ever since the ancient times. Although we have been striving to promote industries in place of agriculture for many decades, yet it is agriculture that has been occupying a glorious position in the Indian economy even today. Even today, agriculture is the basis of the life of more than two-third population of the country. We have been witnessing a constant downward movement in this basis.

\section{Study Area}

Saharanpur is one of the seventy five districts of Uttar Pradesh and is one of the major agricultural districts. It is made up of the alluvial sail-deposits brought down by the rivers flowing in the northern region. The latitudinal range of Saharanpur district is from $29^{\circ} 83^{\prime} \mathrm{N}$ to $30^{\circ} 25^{\prime} \mathrm{N}$ and its longitudinal range is from $77^{\circ} 15^{\prime} \mathrm{E}$ to $78^{\circ} 6^{\prime} \mathrm{E}$. The total area of the district is $3689 \mathrm{sq} \mathrm{Km}$. In the study-scope there are 5 sub divisions and 11 development blocks. The area includes 1575 villages of which 1242 are inhabited and 333 are uninhabited. In 2011 the population of the district was 3467332 of which 1834709 are males and 1632623 are females .Its population density in 2011 was 939 people per Sq Km. The literacy rate of the area is $70.55 \%{ }^{1}$. The district is a dense agricultural based area which suffers favorable conditions for the development of agriculture.

\section{Review of Literature}

The present study of the socio-economic transformation of agricultural development in the district .

If we study the agricultural development in India, is an historical perspective, we find that only after the independence there have been organized efforts in this direction. After the achievement of independence, agriculture and ruler development were given a priority in numerous five-year plans. If we evaluate the work of the geographers in the field of agricultural development in the world and in our country, from the earliest times, effort in this direction were made by the famous U.K geographer L.D Stamp ${ }^{2}$, who discussed the land use of Britain. Apart from this, the work of foreign geographers likes J.L.Buck ${ }^{3}$, Valkin Burg ${ }^{4}$ ，C. P. Burns ${ }^{5}$. Coppock ${ }^{6}$ etc can be considered important and appreciable in this direction. In India S. P Chatterrjee $(1945)^{7}$ discussed the important socio-economic factors on agriculture 
in the 24 pargna districts of West Bengal. Apart from this, the views of Mohammad Shafi $(1951,60,62)^{8}$ of Aligarh Muslim University , Brij Bhushan Singh ${ }^{9}$, and Rajveer Singh ${ }^{10}$ etc have been remarkable in this direction.

\section{Methodology}

Both regional and sequential (arranged) methods have been used for the study presented. In the presented study, the primary and secondary data have been used. This data has been obtained from self conducted surveys and various government and non government offices of the district headquarters.

Study area Saharanpur is a past of the Yamuna plan which is made up of the new deposits of the rivers flowing in the area. Major part of the study area is covered with new fertile alluvial soils, which are classified as loamy, sandy and alkaline soils of Tarai region, for the convenience of study. From the point of view of the drainage system which flows along its tributaries in the region. The climate of the study area is mild monsoon with intense heat in summer and extreme cold in winter. Temperature in summer goes beyond $40^{\circ} \mathrm{C}$ and falls below $5^{\circ} \mathrm{C}$ in winter. The rainfall in the area is around $100 \mathrm{~cm}^{11}$.

The population of 1901 in the study area was 104603 which increased to 3467332 in 2011 . The population growth rate between the two given years has been $231.5 \%$. The population of the area for the year 2001 was 2896863 . The population growth rate of study area has been $19.6 \%$ between 2001 and $2011^{12}$.

Agriculture is the main occupation of the residents of Saharanpur district. Land use studies play an important role in agricultural studies. If we look at the present land use of the study area, we find that $78.83 \%{ }^{13}$ of the area is under cultivation in the year 2016-17, Besides agriculture, the land for other use in $14.18 \% .9 .15 \%$ is meant for forests . $59.08 \%$ of the cultivated area in more than once sown area ${ }^{14}$ .There is a lot of inequality at the sub division and development block levels which is affecting the agicuture at the regional and local levels .

$76.65 \%$ of the total cultivated land is under food crops, wheat, sugarcane and rice are the major crops in the area. Apart from this millet, maize, sorghum, pulses, oilseeds, fodder and potato are also shown on small area. Variety is also visible at block level in the crop model. Wheat (I), sugarcane(II), rice(III), millets(IV) and maize(v) are in the order of I,II,III.IV \& V respectively in crop classification in the study area .

There is a lot of regional variation in the change in the post-independence agricultural environment in the study area, for which physical and cultural factors are mainly responsible. Although efforts for agricultural development in the region 
Impact on Socio-Economic Transformation of Agriculture Development In Saharanpur DistrictA Geographical Study

Dr. Vijay kumar

are seen only in various five years plans yet we got a clear impact only after 1970 when the slogan of "Green Revolution" was given. There has been a huge increase in the area of food grain crops and production in the study area after 1970. The impact of agriculture development is on agricultural production on one hand and on increase is the area of various crops on the other. In Saharanpur district, there is an unprecedented increase in the area of wheat, sugarcane and rice .This growth has increased more than $20 \%$ in some areas and less than $10 \%$ in some areas. In the study area, there has been relatively less increase in the area of other crops. In this context, it is worth mentioning that some crops have seen a reduction in the area.

In Saharanpur district, agricultural productivity has been directly affected by agricultural development. The data of production development in the region expresses a variety of agricultural development. In the area, rice, wheat, sugarcane, potato and lentils have seen a phenomenal growth whereas the total production of coarse grains has declined respectively.

The discussed area in agriculture oriented area. Agriculture is the main source of livelihood here. Therefore, the direct impact of agricultural development is seen directly on the life of the people here. The obvious impact of agricultural development of the Saharanpur district on the socio-economic development is visible in the economic development, results of agricultural development of the Saharanpur district. It is based on technical, chemical, agricultural development and agricultural commercialization and traffic system agriculture. Based on the above mentioned standards, it is also clear that as the agricultural sector has grown rapidly in their study area, the pace of economic development has also accelerated in the area.

As a result of agricultural development in the study area, where there is rapid economic growth, social development is also visible in the area because economic development and social development are complementary and interdependent of each other. For the measurement of social development of the region the main indices of social development are education and its various aspects, the trend of urbanization, health and family welfare and social outlook. Based on the above mentioned standards, rapid social development is visible in the area. Literacy, level of education in the region is visible in urbanization, health and family welfare programs and rapid change in social outlook.

In the study area, on one hand we get the glimpse of social and economic development as a result of agricultural development, on the other hand, in this socio economic development, the differences of the local and regional level is clearly visible. Many natural and human factors are responsible for these socio-economic differences. 
In the study area, in view of the natural facts, human resources, development of various aspects of agriculture and after the socio-economic study of the region and the study of the socio-economic differences, it is extremely necessary to pay attention to the following suggestions for balanced social economic development. Saharanpur district is on a satisfactory position in terms of natural resources, on the other hand, it has, like its region, an excessive rate of population growth. Consequently, population is constantly increasing the burden on agriculture. It needs to be checked. Apart from this, there are many disparities in other aspects of population as well. These need immediate attention, such as low literacy rate, big difference in male and female literacy rate, differences in the growth of ruler and urban population etc. apart from population agriculture is the main source of livelihood of the religion. There is a need to make a comprehensive land use plan for this. Besides, keeping in view the requirements of the area, crop productions as well as the crops which are used as raw materials in industries need to be promoted. In order to increase the production of agriculture, small scale agriculture plans should be made and the efforts should be made for their implementation. The ultimate goal of agricultural development is to get maximum agricultural production from agriculture. For this, the cultivated area, the irrigated area, change in irrigation facilities, optimal use of soil, sophisticated fertilizers and seeds, use of agriculture implements, and improvement in crop cycle, play an important role in the growth of production.

We cannot develop agriculture only by producing agriculture crops unless we get adequate value of those crops. For this marketing administration has to be further strengthened. Moreover, to strengthen the marketing administration, the development of transportation and communication means will have to be developed.

In order to reduce the increasing population load on the agricultural system and speed up the growth of region, agro-based industries will have to be developed. Industrial and agricultural advancement is impossible without industrial advancement. So, a balanced development of both is necessary.

Despite widespread natural resources in the country, poverty, class struggle, dissatisfaction, suffering and regional and other economic difficulties in our life are virtually man made. One of the main reason for this more and more scientific development of natural resources for human welfare. This will lead to harmonized development in every sphere of human life.

By implementing all kinds of socio -economic reforms in the region as well as increasing agricultural productivity, a suitable environment of development can be created and finally it can be said that the suggested measures and programs for the study area, if implemented properly, the coordinated development of the region will 
Impact on Socio-Economic Transformation of Agriculture Development In Saharanpur DistrictA Geographical Study

Dr. Vijay kumar

be possible.

\section{References}

1. Sankhikiya Patrika, District Saharanpur, 2018 Table no $1,7 \& 15$.

2. Stamp. L.D. (1962): "Land of Britain its use and misuse", London 1.

3. Buck, J.L. (1973) : "Land Utilization inChina".

4. Valken Burg, S.V. (1949) : "The project Forward Before the international Geographical Union at Lirbon.

5. Burnes, C.P. (1929) : "Land Resources inventry in Michigan”, Economic Geography, Vol.5, P.No.-1.

6. Coppock, J.T. (1971) : “An Agriculruyral Geography of Great Britain”, London, Page 34.

7. Chaterjee, S.P. (1945): "Land use survey in India".

8. Shafi, M. ( 1951) : "A plea for land use survey, Geographer".

9. Singh, B.B(1988), Agro Industrial Intergrutira Surpluses In Relation to Size Of Land Holiday A case study of U.P ASI, vOL-25, 1 April .

10. Singh Rajveer, Agriculture Devlopment and Socio Economic Transformation in Saharanpur District -An Unpublished Thesis, M.J.R.U Bareilly , 2008

11. Verma ,Sriram \& Vashishtha ,Atmaram : 'Aadrsh Atlas `District Saharanpur, Navbharat Prakashan Mandir,Saharanpur Page 1 to 8 .

12. Census Of India, District Population Saharanpur 2011

13 Sankhikiya Patrika, District Saharanpur,2018 Table no 17.

14. Sankhikiya Patrika, District Saharanpur ,2018 Table no 17. 